\title{
Generalized Weyl's theorems for polaroid operators
}

\author{
C. Carpintero, D. Munoz, E. Rosas, O. García and J. SAnabria
}

\section{ABSTRACT.}

In this paper we establish necessary and sufficient conditions on bounded linear operators for which generalized Weyl's theorem, or generalized $a$-Weyl theorem, holds. We also consider generalized Weyl's theorems in the framework of polaroid operators and obtain improvements of some results recently established in [20] and [29].

\section{REFERENCES}

[1] Aiena, P., Fredholm and Local Spectral Theory, with Application to Multipliers, Kluwer Acad. Publishers (2004)

[2] Aiena, P., Classes of Operators Satisfying a-Weyl's theorem, Studia Math. 169 (2005), 105-122

[3] Aiena, P., Quasi Fredholm operators and localized SVEP, Acta Sci. Mat. (Szeged) 73 (2007), 251-263

[4] Aiena, P., Biondi, M. T. and Carpintero, C., On Drazin invertibility, Proc. Amer. Math. Soc. 136 (2008), 2839-2848

[5] Aiena, P., Carpintero, C. and Rosas, E., Some characterization of operators satisfying a-Browder theorem, J. Math. Anal. Appl. 311, (2005), 530-544

[6] Aiena, P. and Garcia, O., Generalized Browder's theorem and SVEP, Mediterranean J. Math. 4 (2007), 215-228

[7] Aiena, P. and Guillen, R. J., Weyl's theorem for perturbations of paranormal operators, Proc. Amer. Math. Soc. 35 (2007), $2433-2442$

[8] Aiena, P., Guillen, J. and Peña, P., Property ( $w$ ) for perturbations of polaroid operators (2007), Linear Algebra Appl. 428 (2008), 1791-1802

[9] Aiena, P. and Miller, T. L., On generalized a-Browder's theorem, Studia Math. 180 (2007), No. 3, 285-300

[10] Amouch, M., Weyl type theorems for operators satisfying the single-valued extension property, J. Math. Anal. Appl. 326 (2007), 1476-1484

[11] Amouch, M. and Zguitti, H., On the equivalence of Browder's and generalized Browder's theorem, Glasgow Math. J. 48 (2006), 179-185

[12] Berkani, M., On a class of quasi-Fredholm operators, Int. Equa. Oper. Theory 34 (1999), No. 1, 244-249

[13] Berkani, M., Restriction of an operator to the range of its powers, Studia Math. 140(2000), No. 2, 163-175

[14] Berkani, M. and Sarih, M., On semi B-Fredholm operators, Glasgow Math. J. 43 (2001), 457-465

[15] Berkani, M. and Koliha, J., Weyl type theorems for bounded linear operators, Acta Sci. Math. (Szeged) 69 (2003), 359-376

[16] Berkani, M., On the equivalence of Weyl's theorems and genaralized Weyl's theorems, Acta Math. Sinica (English series) 23 (2007), 103-110

[17] Cao, X., Topological Uniform descent and Weyl Type Theorem, Linear Algebra and its Applications 420 (2007), 175-182

[18] Cao, X., Guo, M. and Meng, B., Weyl Type theorems for p-hyponormal and M-hyponormal operators, Studia Math. 163 (2004), No. 2, 177-188

[19] Carpintero, C., García, O., Rosas, E. and Sanabria, J., B-Browder Spectra an Localized SV EP, Rend. Circ. Mat. Palermo 57 (2008), No. 2, 241-255

[20] Curto, R. and Han, Y. M., Generalized Browder's and Weyl's Theorem for Banach Space Operators, J. Math. Anal. Appl. 418 (2007), 385-389

[21] Duggal, B. P., Polaroid operators satisfying Weyl's Theorem, Linear Algebra Appl. 414 (2006), 271-277

[22] Duggal, B. P., Polaroid operators and generalized Browder, Weyl Theorems, Math. Proc. Royal Irish Acad. 108 (2008), No. 2, 149-164

[23] Finch, J. K., The single valued extension property on a Banach space, Pacific J. Math. 58 (1975), 61-69

[24] Grabiner, S., Uniform ascent and descent of bounded operators, J. Math. Soc. Japan 34 (1982), 317-337

[25] Heuser, H., Functional Analysis, Marcel Dekker, New York 1982

[26] Laursen and Newmann Introduction to local spectral theory, Clarendon Press, Oxford 2000

[27] Mbekhta, M. and Müller, V., On the axiomatic theory of the spectrum II, Studia Math. 119 (1996), 129-147

[28] Oudghiri, M., Weyl's and Browder's theorem for operators satysfying the SVEP, Studia Math. 163 (2004), No. 1, 85-101

[29] H. Zguitti, H., A note on generalized Wey'ls theorem, J. Math. Anal. Appl. 316 (2006), No. 1, 373-381

DEPARTMENT OF MATHEMATICS

Universidad de ORIENTE. NÚCleo de SUCRE University

CumANA, VENEZUELA

E-mail address: carpintero.carlos@gmail.com; dmunozesucre.udo.edu.ve;

ennisrafaelegmail.com; ogarcia@sucre.udo.edu.ve; jsanabri@sucre.udo.edu.ve

Received: 12.01.2010; In revised form: 07.02.2011; Accepted: 23.02.2011

2010 Mathematics Subject Classification. 47A10, 47A11,47A53, 47A55.

Key words and phrases. Generalized Weyl's theorems, semi B-Fredholm operator, polaroid operators. 